records (Fig. 3C and D) at Jingbian show four stepped increases in sandsized particle content. The late Pliocene red clay (below L33) contains few sand particles, indicating that the dust was transported in suspension, mainly from a remote source. From $\sim 2.6$ to $\sim 1.2 \mathrm{Ma}$, sand content in interglacial soils remains low, whereas it varies generally between $18 \%$ and $25 \%$ in glacial loess, except for the case of L15 and L16. This suggests that during glacial periods, the desert environment advanced to a location no more than $200 \mathrm{~km}$ from the present northern margin of the Loess Plateau. In the part of the section deposited between $\sim 1.2$ and $\sim 0.7 \mathrm{Ma}$, sand content increases to $\sim 12 \%$ in soils and to $\sim 43 \%$ in loess, with a substantial increase in $>125$ $\mu \mathrm{m}$ particles, implying a large-scale advance of the desert margin during both glacial and interglacial times. Throughout, material deposited in the interval $\sim 0.7-0.2 \mathrm{Ma},>63 \mu \mathrm{m}$ par- ticles range from $\sim 30 \%$ in soils and $\sim 55 \%$ in loess units, with the $>125$ $\mu \mathrm{m}$ particles exceeding $8 \%$. This suggests that the distance between the Loess Plateau and the present desert margin was less than $100 \mathrm{~km}$. During the last two glacial periods, eolian sand was directly deposited at Jingbian, indicating a further southward desert shift.

The Jingbian sand-sized particle record clearly demonstrates that, superimposed on the glacial-interglacial oscillations, the Mu Us Desert experienced significant expansion at $\sim 2.6, \sim 1.2, \sim 0.7$ and $\sim 0.2 \mathrm{Ma}$, directly implying a stepwise southward retreat of the monsoon rainfall belt, associated with a complementary reduction in summer monsoon strength, in the past $3.5 \mathrm{Ma}$. This evolutionary pattern may be causally linked to the Plio-Pleistocene increase in global ice volume, as shown in the marine oxygen isotope record (Fig. 3E).

\section{REFERENCES}

Ding Z.L., Sun, J., and Liu, T., 1999: Stepwise advance of the Mu Us desert since late Pliocene: Evidence from a red clay-loess record, Chin. Sci. Bull. 44:1211-1214

Ding Z.L., Derbyshire, E., Yang, S.L., Yu, Z.W., Xiong, S.F. and Liu, T.S., 2002: Stacked 2.6-Ma grain size record from the Chinese loess based on five sections and correlation with the deep-sea $\delta 180$ record, Paleoceanography 17, 1033, doi: 10.1029/2001PA000725.

Pye K., 1987: Aeolian Dust and Dust Deposits, Academic Press, London.

Shackleton N.J. and Pisias, N.G., 1985: Atmospheric carbon dioxide, orbital forcing, and climate, in: E.T. Sundquist, W.S. Broecker (Eds.), The Carbon Cycle and Atmospheric CO2: Natural Variations, Archean to Present, Geophysical Monograph Series 32. American Geophysical Union, Washington, DC, pp. 303-317.

Shackleton N.J., Berger, A., and Peltier, W.R., 1990: An alternative astronomical calibration of the lower Pleistocene timescale based on ODP site 677, Trans. R. Soc. Edinburgh Earth Sci. 81 251-261.

For full references please consult: www.pages-igbp.org/products/newsletters/ref2005_2.html

\title{
Human-induced Changes of Organic Carbon Storage in Soils of China
}

\author{
Zhengtang Guo ${ }^{1,2}$, Haibin Wu ${ }^{1,2}$ and Changhui Peng ${ }^{3}$ \\ ${ }^{1}$ Institute of Earth Environment, Chinese Academy of Sciences, Xi'an 710075, China; ztguo@mail.igcas.ac.cn \\ ${ }^{2}$ Institute of Geology and Geophysics, Chinese Academy of Sciences, Beijing 100029, China \\ ${ }^{3}$ Institiute of Environment Sciences, University of Quebec at Montreal, Montreal, QC H3C 3P8, Canada
}

In the last two centuries, land use has been a significant source of atmospheric $\mathrm{CO}_{2}$ through conversion of natural vegetation to farming land (Houghton, 1999; Lal, 2004). It has been estimated to be about half of the $\mathrm{CO}_{2}$ emission from the combustion of fossil fuels over the period from 1850 to 1990 (Houghton, 1999). In terrestrial ecosystems, soil organic carbon (SOC) is the largest terrestrial carbon pool. Because SOC generally has a slower turnover rate, it may be preserved for a longer time (IGBPTerrestrial Carbon Working Group, 1998). The huge carbon pool of soils and the significant changes of SOC related to land use by human activity suggest a considerable potential to enhance the rate of carbon sequestration in soils through suitable management, and thereby to decrease the atmospheric $\mathrm{CO}_{2}$ level.

A number of efforts have been carried out to determine the changes of SOC storage induced by land use at regional and global scales. However, because of the high inherent natural variability in the world's soils and variable dynamics of carbon loss under different land uses, accurate estimates of the historic loss are usually hampered by the lack of the required baseline data on soils. More exact estimates on the size of the human-induced changes of SOC storage from natural to current conditions at regional scale are very much needed, especially based on greater data density with direct field measurements. This would provide a basis for a better understanding of the future SOC sequestration from the atmosphere, as well as its role in carbon cycles.

Currently, China has 137.5 million ha of cropland (NSSO, 1998), and the long history of agricultural exploitation and the changes of land use suggest that the terrestrial ecosystem of China would have played an important role in the global carbon cycle. In this study, the spa- tial patterns of soil organic carbon density and storage under natural conditions and those under present-day conditions are investigated comparatively, based on the 34,411 soil profiles analyzed from China's second national soil survey (NSSO, 1998). Among these, 2,553 profiles were considered the most representative based on their geomorphological units, hydrothermal conditions, morphological peculiarities, physicochemical characters, and landuse conditions. According to the land-use conditions, they were then divided into two basic groups. 923 profiles are regarded in this study as natural profiles as they were not cultivated in the land-use history and the profiles had not experienced disturbance by human activity. Their current vegetation are ecologically consistent with the climatic conditions. The other 1,630 profiles were all considered cultivated profiles, including the present-day cultivated soils and those cultivated in the 
past; they were used for evaluating the SOC changes by land use compared to their natural counterparts. The present-day SOC were calculated using the data from the total of 34,411 soil profiles. The difference between the reconstructed SOC under natural conditions and that of the present-day would permit an estimation of SOC changes due to historical land use in China.

Under natural conditions, SOC density decreases from east to west, and a general increase is obvious from north to south in western China, while it decreases from north to south in eastern China (Fig. 1a). Because SOC density is dependent on the bioproductivity and the mineralization intensity of organic matter, this pattern is mainly controlled by hydrothermal climate conditions of China. SOC density values vary from 0.9 to $91.2 \mathrm{~kg} \mathrm{C} \mathrm{m}^{-2}$ in terms of soil groups and mostly range from 4.0 to $13.0 \mathrm{~kg} \mathrm{C} \mathrm{m}^{-2}$. The reconstructed average SOC density is $\sim 8.8 \mathrm{~kg}$ $\mathrm{C} \mathrm{m}^{-2}$, and the total SOC storage is $\sim 77.4 \mathrm{Pg} \mathrm{C}(1015 \mathrm{~g} \mathrm{C}$ ) with $\sim 38.0 \mathrm{Pg}$ $\mathrm{C}$ in the organic horizons and $\sim 39.4$ $\mathrm{Pg} \mathrm{C}$ in the mineral horizons. Under present-day conditions, the basic distribution pattern of SOC density is, thus, roughly similar to that under natural conditions (Fig. 1b). The present-day total SOC storage is 70.3 Pg C, including 32.5 Pg C in the organic horizons and $37.8 \mathrm{Pg} \mathrm{C}$ in the mineral horizons. The average carbon density is $\sim 8.0 \mathrm{~kg} \mathrm{C} \mathrm{m}^{-2}$.

Comparing the spatial distribution and storage of SOC in the above two kinds of soils (Fig. 1d-f) reveals that $\sim 31 \%$ of the total soil surface ( $57 \%$ of the cultivated soil subgroups) has experienced a significant carbon loss, ranging from $40 \%$ to $10 \%$ relative to their natural counterparts. The most significant carbon loss is observed for the non-irrigated soils (dry farmland, Fig. 1c) within a semi-arid/semi-humid belt from northeastern to southwestern China, with the maximum loss occurring in northeast China. Conversely, the SOC in $\sim 5 \%$ of land surface $(\sim 26 \%$ of the cultivated soil subgroups) has increased, most in the paddy and irrigated soils in northwest China. Insignificant changes are observed

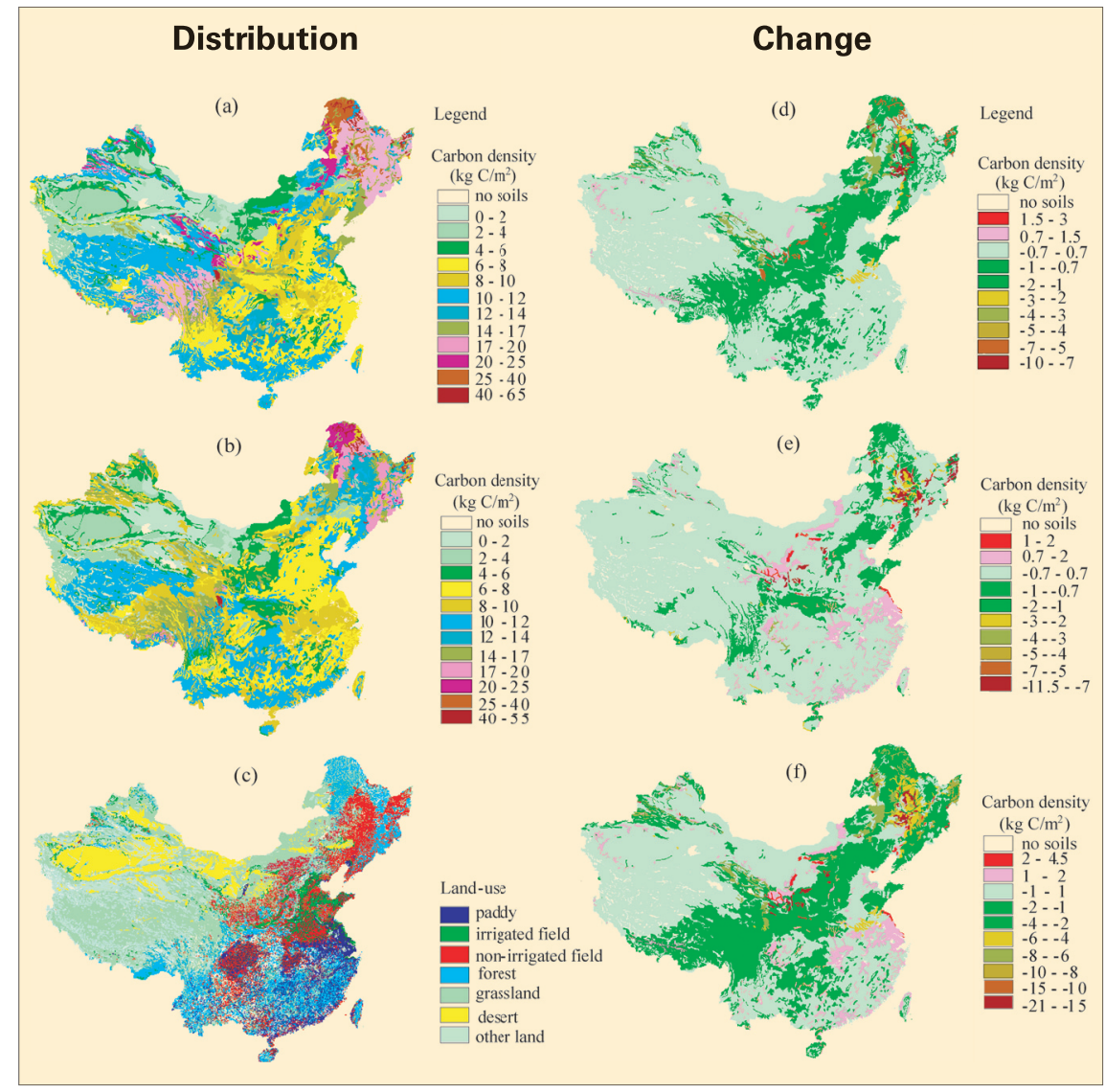

Fig. 1: Spatial distribution of SOC density, changes of SOC density and land use in China. (a) Distribution of SOC density under natural conditions, (b) Distribution of SOC density under present-day conditions, (c) Distribution of land use in China, (d) Distribution of SOC density changes in organic horizons, (e) Distribution of SOC density changes in mineral horizons, (f) Distribution of profile SOC density changes.

within $\sim 64 \%$ of the considered surface, mostly corresponding to forest soils in southern China, grassland and desert soils in northwest China, as well as irrigated soils in eastern China. Overall, $7.1 \mathrm{Pg} \mathrm{C}$ of SOC storage has been lost and $\sim 0.8 \mathrm{~kg} \mathrm{C}$ $\mathrm{m}^{-2}$ SOC density has been decreased due to increasing human activities, in which the loss in organic horizons has contributed to $\sim 77 \%$ (Fig. 1d). This total loss of SOC in China induced by land use represents $~ 9.5 \%$ of the world's SOC decrease. This amount is equivalent to $\sim 3.5 \mathrm{ppmv}$ of the atmospheric $\mathrm{CO}_{2}$ increase.

Because $\sim 78 \%$ of the currently cultivated soils in China have been degraded to a low/medium productivity (NSSO, 1998) and most of the SOC loss has occurred in cultivated soils without irrigation, improved land management, such as the development of irrigation practices, conservation tillage and other systems of sustainable soil management, would have considerable potential for restoring the SOC stor- age. Assuming a restoration of $~ 50 \%$ of the lost SOC during the next 20-50 years, the soils in China would absorb $\sim 3.5 \mathrm{Pg} \mathrm{C}$ of carbon and thus might significantly contribute to carbon sequestration from the atmosphere under the global warming scenario.

\section{ReFerences}

Houghton, R.A., 1999: The annual net flux of carbon to atmosphere from changes in land use 18501990. Tellus, 51B: 298-313.

IGBP Terrestrial Carbon Working Group, 1998: The terrestrial carbon cycle: implications from the Kyoto Protocol. Science, 280, 1393-1394.

Lal, R., 2004: Soil carbon sequestration impacts on global climate change and food security. Science, 304, 1623-1627.

National Soil Survey Office (NSSO), 1998: Soils of China. China Agricultural Press, Beijing (in Chinese).

Wu, H., Guo, Z. and Peng, C., 2003: Distribution and storage of soil organic carbon in China. Global Biogeochemical Cycles, 17(2): 1048-1058

Wu, H., Guo, Z., and Peng, C., 2003: Land use induced China. Global Change Biology, 9: 305-315. changes of organic carbon storage in soils of 